\title{
Desogestrel for preventing a premature luteinizing hormone (LH) surge in a cycle for oocyte cryopreservation
}

\author{
Camila Karsburg Bessow ${ }^{1 *}$, Rafaela Colle Donato ${ }^{1}$, João Sabino Lahorgue da Cunha Filho ${ }^{1,2}$ \\ ${ }^{1}$ Centro de Reprodução Humana Insemine, Porto Alegre, RS, Brasil \\ 2Universidade Federal do Rio Grande do Sul (UFRGS), Porto Alegre, RS, Brasil
}

\begin{abstract}
Objectives:The advance of cryopreservation techniques turn possible the use of new strategies for LH supression during in vitro fertilization (IVF) cycles. Methods: The use of progesterone instead of gonadotropin-releasing hormone (GnRH) analogues seems to be a feasible option. Desogestrel is a progesterone broadly known and accepted in the context of contraception, with a good tolerability and low cost, in addition to a potent anti-ovulatory potency. Results: The present case is the first describing a succesfully controlled ovarian hyperstimulation $(\mathrm{COH})$ for social oocyte cryopreservation using desogestrel $75 \mathrm{mcg}$ as a LH blocker in a healthy 35 -year-old woman. Conclusions: the use of progesterone for LH supression seems to be a great option in the context of oocyte cryopreservation, since it is safe, less expensive and patient-friendly, avoiding the daily injections of GnRH analogues.
\end{abstract}

Keywords: progesterone; desogestrel; in vitro fertilization; cryopreservation.

\section{Introduction}

Traditionally, LH suppression is achieved by using a GnRH agonist or antagonist. However, improved cryopreservation techniques and freeze-all strategies are introducing new concepts in this field, including the possibility of using progesterone instead of $\mathrm{GnRH}$ analogues. ${ }^{1}$

Besides the fact that $\mathrm{GnRH}$ analogues are more expensive than progesterone, the use of GnRH agonists can increase the treatment length and the risk of ovarian hyperstimulation syndrome, and on the other side, GnRH antagonists have a variable failure rate in preventing the LH surge (up to 38\%). ${ }^{2}$ The use of oral medroxyprogesterone $10 \mathrm{mg} / \mathrm{day}$ was previously shown to effectively prevent the LH surge during $\mathrm{COH}$ for IVF in women with a normal ovarian reserve, without impacting embryo development or pregnancy rates after frozen embryo transfer. ${ }^{1}$ Recently, the use of dydrogesterone with the same purpose was also effective in preventing the premature LH surge. ${ }^{3}$ However, other types of progesterone have not been tested. Desogestrel is a progesterone that is broadly known and accepted in the context of contraception and that has good tolerability and low cost. Progestins have different pharmacological properties depending on their similarity with progesterone or testosterone; the anti-ovulatory potency varies among progestins, and desogestrel, a third-generation testosterone derivative, has been described as one of the most potent anti-ovulatory agents. ${ }^{4}$

Other studies have shown that during the normal follicular phase, progesterone decreases the LH pulse frequency, thereby inhibiting the LH surge and, consequently, reducing serum LH levels. ${ }^{5}$ Furthermore, in a study of desogestrel 75 mcg as a contraceptive, the rate of ovulation was only $1.7 \%$, showing the ability of this progesterone to block the LH surge and ovulation. ${ }^{6}$ Therefore, the usefulness of desogestrel as an LH blocker during COH in a woman who desired social oocyte cryopreservation is presented for the first time herein.

Financial support: None.

Conflicts of interest: The authors declare no conflicts of interest.

Submitted: January 03, 2019.

Accepted: September 03, 2019.

The sutdy was carried out at Centro de Reprodução Humana Insemine, Porto Alegre, RS, Brasil.

Copyright Bessow et al. This is an Open Access article distributed under the terms of the Creative Commons Attribution License, which permits unrestricted use, distribution, and reproduction in any medium, provided the original work is properly cited. 


\section{Case report}

The patient was a healthy 35-year-old woman with regular cycles of 30 days, a body mass index of $23.5 \mathrm{~kg} / \mathrm{m}^{2}$ and an antral follicle count of 15 measured by transvaginal ultrasound in the early follicular phase. She received human menopausal gonadotropin (hMG) for 10 days (total dose $2850 \mathrm{IU}$, dosage adjustment according to ovarian response by ultrasound) and desogestrel $75 \mathrm{mcg}$ starting at day 1 of ovarian stimulation. The final stage of oocyte maturation was induced with human chorionic gonadotropin (hCG) $5000 \mathrm{IU}$ in the day that at least 3 follicles reached a diameter of at least $17 \mathrm{~mm}$. A total of 8 oocytes were retrieved 36 hours later; 5 were stage metaphase II (MII) and cryopreserved by vitrification. Hormones were measured at cycle day 7 (LH $1.7 \mathrm{mlU} / \mathrm{mL}$, oestradiol $1555 \mathrm{pg} / \mathrm{mL}$ and progesterone $0.76 \mathrm{ng} / \mathrm{mL}$ ) and day 10 (before hCG administration; LH $0.5 \mathrm{mlU} / \mathrm{mL}$, oestradiol $3411 \mathrm{pg} / \mathrm{mL}$ and progesterone $1.05 \mathrm{ng} / \mathrm{mL}$ ), confirming adequate LH suppression during the treatment period without interfering with the oestradiol rise. The endometrium remained atrophic during the entire stimulation (maximum measure, $5 \mathrm{~mm}$ ). Desogestrel was administered between days 1 and 10 of $\mathrm{COH}$.

\section{Discussion}

This case is the first in the literature reporting the use of desogestrel as an inhibitor of LH surges during $\mathrm{COH}$, with appropriate hormonal profiles and good reproductive results, suggesting that desogestrel is an alternative to medroxyprogesterone and GnRH analogues. Progesterone has several advantages over GnRH analogues for this purpose, such as cost, effectiveness and patient-friendly administration (daily oral tablets versus daily injections). Figure 1 shows the different protocols when GnRH antagonist and progesterone are used.

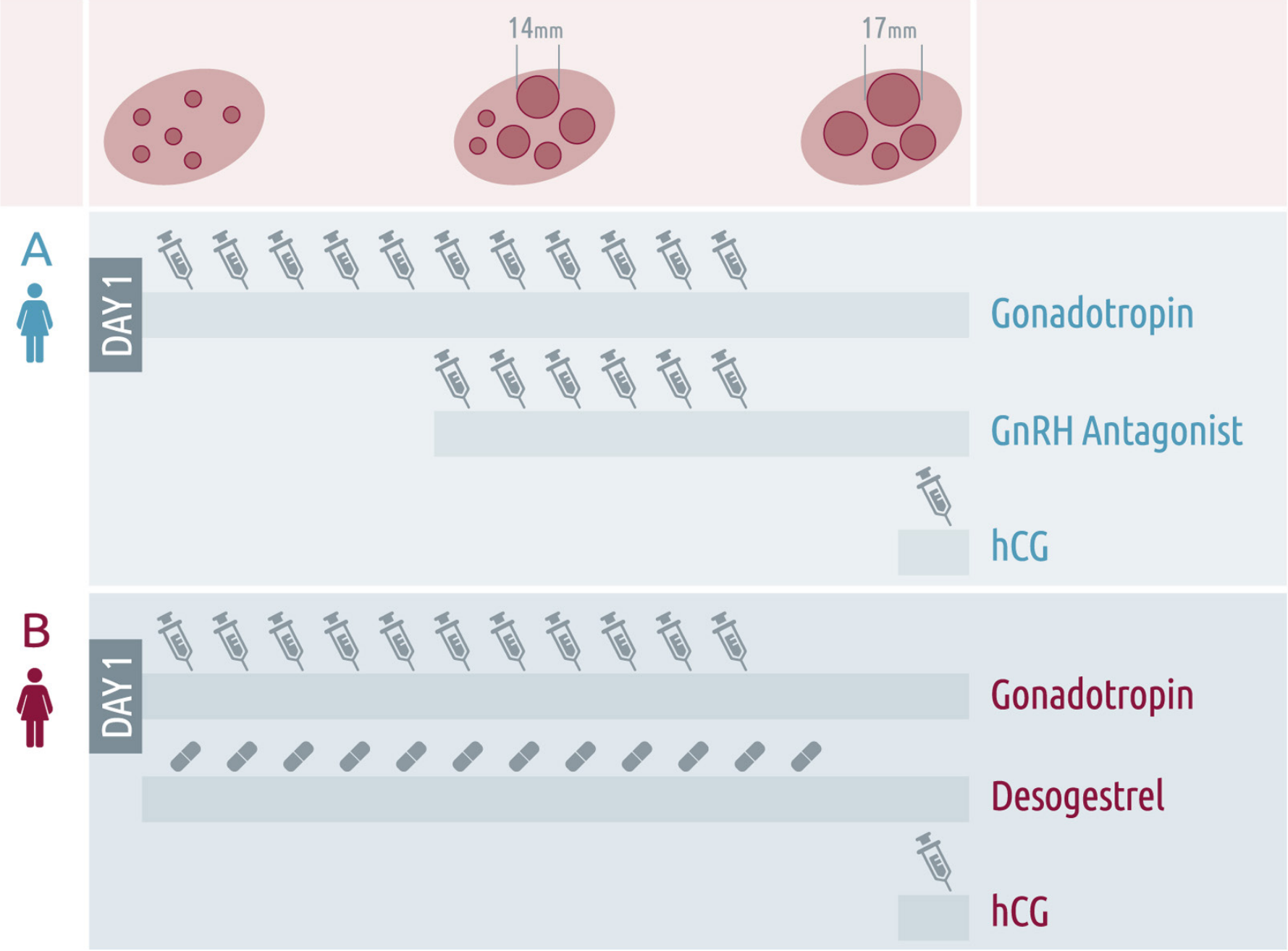

Figure 1. The differences between treatment regimens: patient $A$ has received only injections during the ovarian stimulation, two a day the most of the time; and patient B received only one injection a day + desogestrel oral pills, showing the patient-friendly scheme on treatment B. 
Furthermore, the use of progesterone in this context is only possible because of advances in vitrification techniques, since the endometrium is not favourable for embryo implantation in the same cycle of ovarian stimulation. Recently, the use of advanced vitrification techniques has become widespread, and survival rates of over $90 \%$ with similar or even better pregnancy chances than with fresh embryo transfer have been reported. ${ }^{7}$ In addition, cryopreservation represents a major step in female fertility preservation and it is important to make these procedures easier and less distressing without compromising the results.

The goal for the next years should be to apply these procedures for patients in the context of oncofertility and egg donation. Another group that could benefit from this approach is patients with polycystic ovary syndrome, as a recent study showed better outcomes with the freeze-all strategie for these women. ${ }^{8}$ Also, the poor responders group of patients could benefit from the use of progesterone, since they are more likely to have a failure with the GnRH antagonist. A randomized controlled trial is being conduced to investigate the potential of progestin(medroxyprogesterone) for poor responders undergoing IVF. ${ }^{9}$

Further controlled trials should be performed to endorse the use of this new treatment regimen and to ascertain the ideal dose and day of initial administration; nevertheless, the results suggest an easier and safer potential strategy to prevent the LH rise in IVF/cryopreservation cycles.

\title{
Reference
}

1. Kuang Y, Chen Q, Fu Y, Wang Y, Hong Q, Lyu Q, et al. Medroxyprogesterone acetate is an effective oral alternative for preventing premature luteinizing hormone surges in women undergoing controlled ovarian hyperstimulation for in vitro fertilization. Fertil Steril. 2015;104(1):62-70.e3. http://dx.doi.org/10.1016/j.fertnstert.2015.03.022. PMid:25956370.

2. Bosch E, Valencia I, Escudero E, Crespo J, Simón C, Remohí J, et al. Premature luteinization during gonadotropin-releasing hormone antagonist cycles and its relationship with in vitro fertilization outcome. Fertil Steril. 2003;80(6):1444-9. http://dx.doi. org/10.1016/j.fertnstert.2003.07.002. PMid:14667881.

3. Iwami N, Kawamata M, Ozawa N, Yamamoto T, Watanabe E, Moriwaka O, et al. Watanabe EMoriwaka O. New trial of progestin primed ovarian stimulation using dydrogesterone versus a typical GnRH antagonist regimen in assisted reproductive technology. Arch Gynecol Obstet. 2018;298(3):663-71. http://dx.doi.org/10.1007/s00404-018-4856-8.

4. Schindler AE, Campagnoli C, Druckmann R, Huber J, Pasqualini JR, Schweppe K, et al. Classification and pharmacology of progestins. Maturitas. 2003;46(Suppl 1):S7-16. http://dx.doi.org/10.1016/j.maturitas.2003.09.014. PMid:14670641.

5. Soules MR, Steiner RA, Clifton DK, Cohen NL, Aksel S, Bremner WJ. Progesterone modulation of pulsatile luteinizing hormone secretion in normal women. J Clin Endocrinol Metab. 1984;58(2):378-83. http://dx.doi.org/10.1210/jcem-58-2-378. PMid:6420438.

6. Milsom I, Korver T. Ovulation incidence with oral contraceptives: a literature review. J Fam Plann Reprod Health Care. 2008;34(4):23746. http://dx.doi.org/10.1783/147118908786000451. PMid:18854069.

7. Massin N. New stimulation regimens: Endogenous and exogenous progesterone use to block the LH surge during ovarian stimulation for IVF. Hum Reprod Update. 2017;23(2):211-20. http://dx.doi.org/10.1093/humupd/dmw047. PMid:28062551.

8. Chen ZJ, Shi Y, Sun Y, Zhang B, Liang X, Cao Y, et al. Fresh versus Frozen Embryos for Infertility in the Polycystic Ovary Syndrome. N Engl J Med. 2016;375(6):523-33. http://dx.doi.org/10.1056/NEJMoa1513873. PMid:27509101.

9. Wang Y, Kuang Y, Chen Q, Cai R. Gonadotropin-releasing hormone antagonist versus progestin for the prevention of premature luteinising hormone surges in poor responders undergoing in vitro fertilisation treatment: study protocol for a randomised controlled trial. Trials. 2018;19(1):455. http://dx.doi.org/10.1186/s13063-018-2850-x. PMid:30134964.

\author{
*Correspondence \\ Camila Karsburg Bessow \\ Centro de Reprodução Humana Insemine, \\ Av Dr Nilo Peçanha, 2825, 905 \\ CEP: 91330-001, Porto Alegre, RS, Brasil \\ Tel.: +55 (51) 3388-1212 \\ E-mail: k.bessow@gmail.com
}

\section{Authors information}

CKB - Master's degree in Human Reproduction, Universidade Federal do Rio Grande do Sul; RCD - Master's degree in Human Reproduction, Universidade Federal do Rio Grande do Sul; JSLCF - PhD in Human Reproduction, Universidade Federal do Rio Grande do Sul, Professor at Universidade Federal do Rio Grande do Sul.

\section{Authors contribution}

All authors read and approved the final manuscript. CKB analyzed and interpreted the patient data and was a major contributor in writing the manuscript. RCD made substantial contributions to conception of the paper, acquisition and interpretation of data, JSLCF have been involved in drafting the manuscript, revising it critically and given final approval of the version. 